\title{
QM/MM Study for the Reaction Mechanisms of Benzyl Alcohol with Dimethyl Carbonate over a Faujasite Zeolite Catalyst
}

\author{
Shu Xian Chong ${ }^{1}$, Habibah A. Wahab ${ }^{2}$ and Hassan Hadi Abdallah ${ }^{1 *}$ \\ ${ }^{1}$ School of Chemical Sciences, Universiti Sains Malaysia, 11800 Penang, Malaysia \\ ${ }^{2}$ School of Pharmaceutical Sciences, Universiti Sains Malaysia, 11800 Penang, Malaysia \\ Received 3 August 2011, Revised 31 August 2011, Accepted 17 September 2011, Available online 4 December 2011
}

\section{ABSTRACT}

Benzyl methyl ether (BME) compounds are largely synthesized by the industry for use as a starting material for the synthesis of other organic compounds. In order to achieve the target of green chemistry, BME can be synthesized from benzyl alcohol and dimethyl carbonate (DMC) using a zeolite catalyst. DMC is a non toxic compound and a good methylating and carboxymethylating agent. The methylation and carboxymethylation reactions of benzyl alcohol over a 36T extended framework was investigated by ONIOM(HF/3-21g:UFF). Two pathways for the methylation reaction were found, where the first involving two transition states (TS) and the second only a single TS. Methylation via the two-TS pathway has a lower activation energy compared to the single-transition state pathway. Also, the methylation reaction is kinetically more favorable than the carboxymethylation reaction and this finding agrees well with the previous experimental results. The rate constant for the studied reactions were calculated by using the transition state theory and the rate determining step was determined.

| Benzyl methyl ether | Zeolite | ONIOM |

\section{INTRODUCTION}

Benzyl methyl ether (BME) is a non-symmetrical ether [1] that exists naturally in spices, herbs, mints, dried fish products, mushroom, tea, juices and alcoholic beverages [2]. Despite that, BME is also used as a solvent for organic compounds and a starting material for the synthesis of other organic compounds [3]. The conventional method to prepare BME is by the Williamson ether synthesis. As shown in Eq. (1), the neucleophile (alkoxide ion) is involved in a $\mathrm{S}_{\mathrm{N}} 2$ (bimolecular nucleophilic substitution) attack on an unhindered primary alkyl halide and leads to ether production. The alkoxide ion is produced by adding a suitable alkali metal or hydride, such as sodium, potassium, or sodium hydride to the alcohol [1].

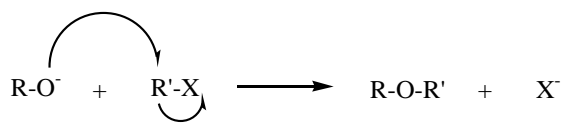

where $\mathrm{R}$ is the phenyl or alkyl group, $\mathrm{R}$ ' is the alkyl group and $\mathrm{X}$ is a halide.

Unfortunately, this reaction involves the use of toxic and corrosive reactants with the corresponding concern of environmental pollution and health risks $[4,5]$.

Corresponding author at: School of Chemical Sciences,

Universiti Sains Malaysia, 11800 Penang, Malaysia

E-mail addresses: hwchems@gmail.com (Hassan Hadi Abdallah)
A same amount of alkaline halide and alcohol must be added in order to allow a complete reaction to occur. As a result, the same amount of inorganic salt produced need to be discarded as waste [6,7]. In order to achieve the desired green production of BME, the synthesis can be done with a nucleophile (alcohol) and dimethyl carbonate (DMC) over an acidic or basic catalyst have been reported extensively [5-10]. DMC is a well known non-toxic alkylating agent that can be used to replace the alkyl halides for less harmful methylation and carboxymethylation reactions [11]. Selva et al. (2008) reported that the faujasite zeolite catalyst allows both methylation and carboxymethylation reactions to occur simultaneously at temperature $165-168{ }^{\circ} \mathrm{C}$ [5]. Thus, the two main possible products formed are benzyl methyl carbonate (BMC) and BME, as shown in Eq. (2). Moreover, as the temperature is increased, BMC will undergo decarboxylation to form BME [5], as shown in Eq. (3).
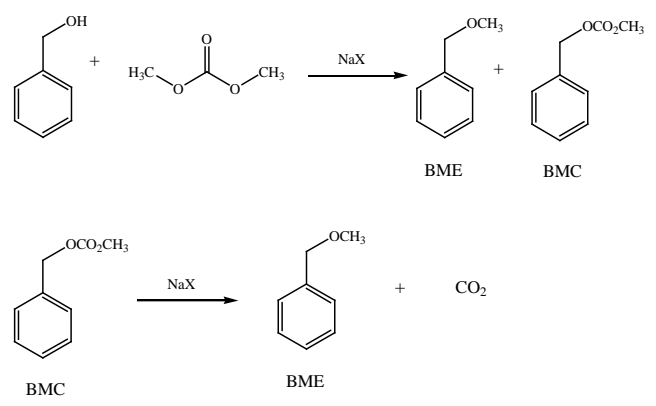
Even though these experimental studies have successfully synthesized BME with benzyl alcohol and DMC over a zeolite catalyst, however, the mechanisms pathway still remain unclear. The aim of this study was to predict the optimized geometries of the different complexes in the TS and ground state (GS) over a 36T cluster of zeolite. The energy profiles of the reactions were calculated and the mechanisms of the methylation and carboxymethylation of benzyl alcohol over a faujasite zeolite is discussed.

\section{EXPERIMENTAL}

The monoclinic crystal structures of faujasite zeolite were constructed with the reference to the lattice structure proposed [12]. The $3 \mathrm{~T}$ cluster $\left[\equiv \mathrm{SiOAl}(\mathrm{OH})_{2} \mathrm{O}(\mathrm{H}) \mathrm{Si} \equiv\right]$ represents the smallest cluster and the active site of the NaX zeolite [13-19]. In this study, an extended the zeolite framework to a $36 \mathrm{~T}$ quantum cluster, which connected to the active site of two supercages $[13,14,16,18]$. One of the silicon atoms in the faujasite zeolite is replaced with an aluminium atom [13] and the charge balancing cation (sodium atom) was added to the zeolite for neutralization [20]. The dangling bonds were terminated by $\mathrm{H}$ atoms $[13,28,20,21]$ and the $\mathrm{Si}-\mathrm{H}$ bonds were fixed along $\mathrm{Si}-\mathrm{O}$ bonds at $1.47 \AA[13,18]$. The system was calculated with the ONIOM(HF/3-21G:UFF) method where the active site of the $36 \mathrm{~T}$ quantum cluster $\left[\equiv \mathrm{SiOAl}(\mathrm{OH})_{2} \mathrm{O}(\mathrm{H}) \mathrm{Si} \equiv\right]$ and the reactants were allowed to relax while the extended system was fixed at the Cartesian coordinates $[13,14,16]$. The frequencies were calculated to determine whether the species is at the GS or TS. Also, the frequencies were used to determine the partition functions of the rate constant calculations [22]. Calculations were performed using the Gaussian 03 [23] software under a Linux operating system. GaussView 03 and Chemcraft softwares were used to view the geometry of molecules and vibrational frequencies.

The energy profile's reference point is the summation of to the isolated benzyl alcohol, DMC and the zeolite system. The adsorption energy of both reactants over the zeolite is calculated as follow [24]:

$\Delta E_{\text {(ads) }}=E_{\text {(alcohol-DMC-zeolite) }}-E_{\text {(alcohol) }}-E_{\text {(DMC) }}-E_{\text {(zeolite) }}$

\section{RESULTS \& DISCUSSION}

\subsection{Adsorption of Reactants onto the Zeolite Surface}

At the zeolite surface, the benzyl alcohol undergoes nucleophile activation [5], which results in an elongation of the $\mathrm{O}-\mathrm{H}$ bond. Meanwhile, DMC undergoes electrophilic activation, where $\mathrm{O}-\mathrm{CH}_{3}$ bond elongation is observed [6]. Figure 1 shows the single benzyl alcohol adsorption structure (Fig. 1.0a), whereas DMC is observed to have two different adsorption structures (Fig. 1.0b and c).

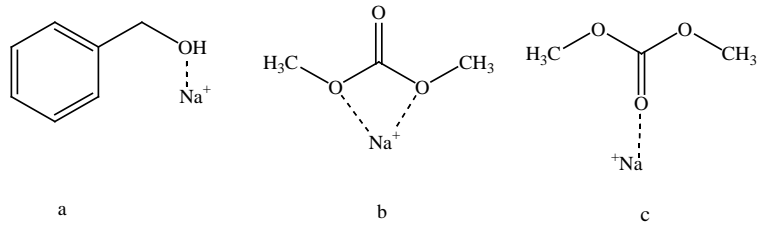

Fig. 1.0 The adsorption structures of (a) benzyl alcohol and (b,c) dimethyl carbonate (DMC) at the of zeolite surface

The optimized adsorption structure of DMC by two oxygen atoms (Fig. 1.0b) is thermodynamically more favourable due to the existence of two electrostatic interactions between the $\mathrm{Na}^{+}$ion and two oxygen atoms. Before the coadsorption of both reactants, the $\mathrm{Na}-\mathrm{Al}$ distance was 2.741 $\AA$. During the co-adsorption of both reactants (GS1), the $\mathrm{Na}-\mathrm{Al}$ distance lengthened by $0.778 \AA$ to $3.519 \AA$. The benzyl alcohol is observed in the same plane with the active site of the zeolite and the DMC is co-adsorbed perpendicularly to the zeolite surface (Fig. 1.1). The benzyl alcohol adsorbed weakly onto the zeolite surface through $\mathrm{H}_{\text {alcohol }}-\mathrm{O}_{\text {zeolite }}(\mathrm{H}-\mathrm{O} 1)$ hydrogen bond, with a distance of $1.628 \AA$, whilst DMC co-adsorbed nearby the zeolite surface (Fig. 1.1). The theoretically calculated adsorption energy of reactants over zeolite is $-77.82 \mathrm{kcal} / \mathrm{mol}$ (Fig. 1.2).

Subsequently, these co-adsorbed reactants will undergo a change to the TS1, where the benzyl alcohol is observed adsorbed onto a different oxygen atom of the zeolite surface due to the change in optimization steps. A hydrogen bond is observed between the $\mathrm{H}$ atom of benzyl alcohol with the $\mathrm{O}$ atom of zeolite adjacent to the Si1 atom with a distance of 1.911 A (Fig. 1.1). In the GS2, the $\mathrm{Na}^{+}$ ion moved closer to the $\mathrm{O} 3$ atom of benzyl alcohol and the $\mathrm{O} 3-\mathrm{H}$ bond is weakened to $1.000 \AA$ and the $\mathrm{Na}^{+}$metal ion of faujasite has reduced the benzyl alcohol into a benzyl alkoxide ion in the GS2, as shown in Eq. 4.

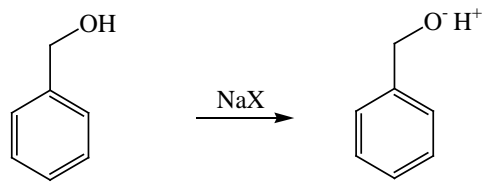

The computed energies at TS1 and GS2 are +4.80 and -8.23 $\mathrm{kcal} / \mathrm{mol}$, respectively (Fig. 1.2).

\subsection{Methylation of Benzyl Alcohol}

\section{2 (a) Pathway 1: Methylation of Benzyl Alcohol with Two TS}

The methylation reaction occurs when the alkoxide ion formed in the GS1 attacks the unhindered primary alkyl group of DMC and leads to the production of BME and methyl carbonic acid (Eq. 5). 


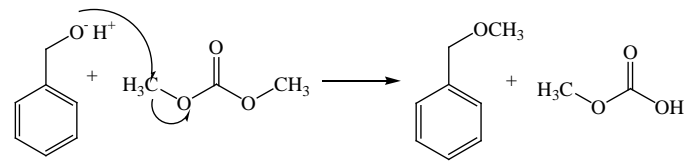

In the TS2, when the nucleophile (benzyl alcohol) attacks the DMC, $\mathrm{O}_{\text {alcohol }}-\mathrm{H}_{\text {alcohol }}(\mathrm{O} 3-\mathrm{H})$ and $\mathrm{C}_{\mathrm{DMC}}-\mathrm{O}_{\mathrm{DMC}}$ (C4-O4) bonds were cleaved and followed by the formation of the $\mathrm{C}_{\mathrm{DMC}}-\mathrm{O}_{\text {alcohol }}(\mathrm{C} 4-\mathrm{O} 3)$ and $\mathrm{O}_{\mathrm{DMC}}-\mathrm{H}_{\text {alcohol }}(\mathrm{O} 4-\mathrm{H})$ bonds to produce BME and methyl carbonic acid. The $\mathrm{H}$ atom of methyl carbonic acid was observed interacting with the $\mathrm{O} 3$ atom of BME with a distance of 1.626 Á (Fig. 1.0) and caused the $\mathrm{O} 4-\mathrm{H}$ bond distance of methyl carbonic acid has lengthened to $1.001 \AA$. The activation energy for the TS2 is predicted to be $+7.49 \mathrm{kcal} / \mathrm{mol}$ (Fig. 1.2).

Previous theoretical studies have suggested that carbonic acid is less stable than the reactants (water and carbon dioxide) in the gas phase [25-31]. Therefore, we assume that methyl carbonic acid will react further to form a more stable compound. Also, in the GS3, the O4- $\mathrm{H}$ bond is slightly lengthened to $1.036 \AA$ and this indicates the stability of the bond is weakened and is ready to undergo further reaction. TS3 occurs when the methyl carbonic acid is deprotonated by the alkaline $\mathrm{Na}^{+}$ion to form an anionic intermediate and followed by the lone pair of electrons of oxygen migrates to the adjacent carbon atom to form the $\mathrm{C}=\mathrm{O}$ bond and the $\mathrm{C}-\mathrm{O}$ bond will break simultaneously. Therefore, carbon dioxide is emitted and the alkoxide ion is protonated to become methanol (Eq. 6).

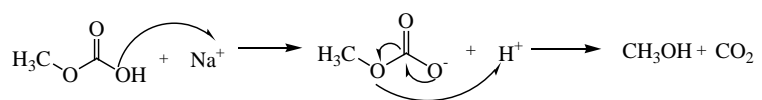

In the $\mathrm{TS} 3$, the $\mathrm{C} 3-\mathrm{O} 5$ bond in the methyl carbonic acid cleaved and $\mathrm{O} 5-\mathrm{H}$ bond formed simultaneously to produce carbon dioxide and methanol. The methanol is observed adsorbed on the zeolite surface through $\mathrm{O}_{\text {zeolite }}-\mathrm{H}_{\text {alcohol }}(\mathrm{O} 2-\mathrm{H})$ hydrogen bond, with a distance of $1.767 \AA$ (Fig. 1.0) and the O5-H bond of methanol was at $0.983 \AA$. The predicted activation energy of TS3 is +13.39 $\mathrm{kcal} / \mathrm{mol}$ (Fig. 1.2).

\section{2 (b) Pathway 2: Methylation of Benzyl Alcohol with a Single TS}

The methylation Pathway 2 only involves a single TS (TS4) to produce BME with carbon dioxide and methanol as the side products (Eq. 7).

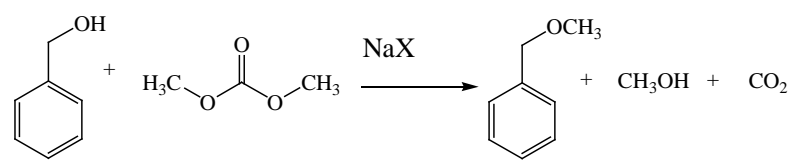

In the TS4, formation of BME and carbon dioxide are observed moved apart from the zeolite surface but the methanol is absorbed onto the zeolite active site via hydrogen bonding of $\mathrm{O}_{\text {zeolite }}-\mathrm{H}_{\text {alcohol }}(\mathrm{O} 1-\mathrm{H})$ with a bond distance of $1.683 \AA$ (Fig. 1.1). The predicted activation energy in the methylation Pathway 2 (TS4) is +12.91 $\mathrm{kcal} / \mathrm{mol}$ (Fig. 1.3) and it is almost double the activation energy of the Pathway 1 of the TS2 $(7.49 \mathrm{kcal} / \mathrm{mol})$ and it is slightly lower than the activation energy in the TS3 (Fig. 1.2). Therefore, the methylation Pathway 2 is kinetically less stable compared to the Pathway 1 and it is not favorable in the methylation reaction.

\subsection{Carboxymethylation of Benzyl Alcohol}

The carboxymethylation reaction occurs when the alkoxide ion attacks the carbonyl carbon atom of DMC and leads to BMC and methanol production (Eq. 8).

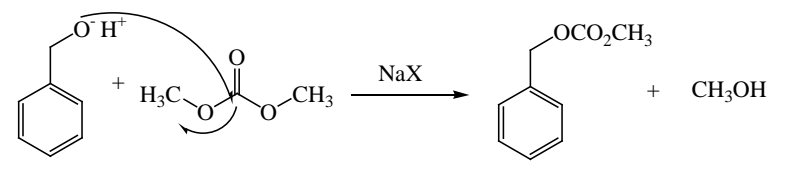

In the TS5, the $\mathrm{O}_{\text {alcohol }}-\mathrm{H}_{\text {alcohol }}(\mathrm{O} 3-\mathrm{H})$ and $\mathrm{C}_{\text {DMC }}-\mathrm{O}_{\text {DMC }}(\mathrm{C} 3-\mathrm{O} 4)$ bonds are observed to be cleaved and followed by the formation of the $\mathrm{C}_{\mathrm{DMC}}-\mathrm{O}_{\text {alcohol }}(\mathrm{C} 3-\mathrm{O} 3)$ and $\mathrm{O}_{\mathrm{DMC}}-\mathrm{H}_{\text {alcohol }}(\mathrm{O} 4-\mathrm{H})$ bonds to form $\mathrm{BMC}$ and methanol respectively. The methanol is observed located beside the BMC and slightly moved apart from the zeolite surface (Fig. 1.1). The computed activation energy of TS5 is +14.00 $\mathrm{kcal} / \mathrm{mol}$ (Fig. 1.4), which is higher than the activation energy of the methylation Pathway 1 and 2 (TS2, TS3 and TS4). In short, the carboxymethylation reaction is kinetically less stable compared to the methylation reaction and it is not favored in this reactions. This finding agrees well with the previously reported experimental data which revealed that the carboxymethylation reaction yielded a low percentage of products [5]. However, in the GS6, the methanol is found adsorbed on the zeolite surface via a $\mathrm{O}_{\text {zeolite }}-\mathrm{H}_{\text {alcohol }}(\mathrm{O} 1-\mathrm{H})$ hydrogen bond (Fig. 1.1).

At a higher reaction temperature, BMC eventually convert to BME and carbon dioxide as shown in Eq. 9.

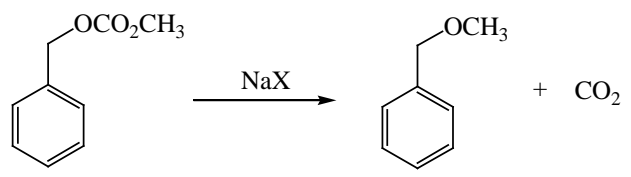

In the TS6, the BME, carbon dioxide and methanol are formed and the BME and methanol are observed located beside one another but the carbon dioxide is moving away from the zeolite surface (Fig. 1.1). The predicted activation energy in the TS6 is $+16.79 \mathrm{kcal} / \mathrm{mol}$ (Fig. 1.4) and it is higher than the TS energies in both of the methylation 
Pathways (TS2, TS3 and TS4). This finding is supported by the previous experimental work which demonstrated that at reaction temperature, the methylation reaction predominates and the BMC undergoes decarboxylation reaction to produce BME and carbon dioxide. Lastly, in the GS7, the methanol is moving towards the zeolite surface and adsorbed on it via a $\mathrm{O}_{\text {zeolite }}-\mathrm{H}_{\text {alcohol }}(\mathrm{O} 1-\mathrm{H})$ hydrogen bond (Fig. 1.1).

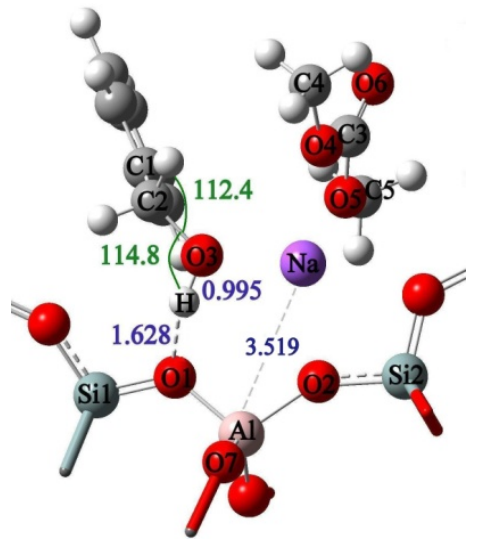

GS1

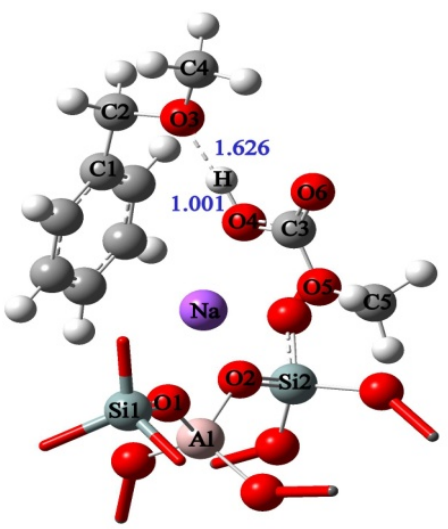

TS2

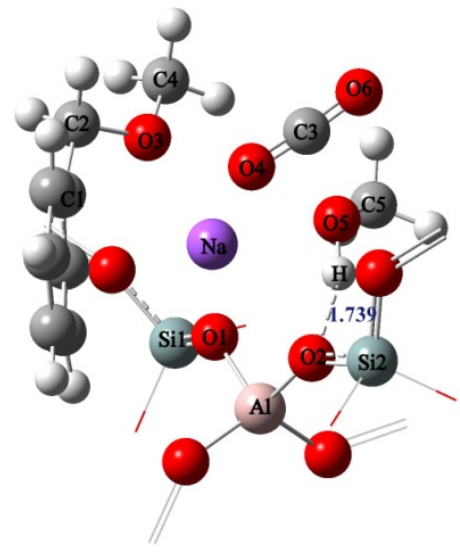

GS4

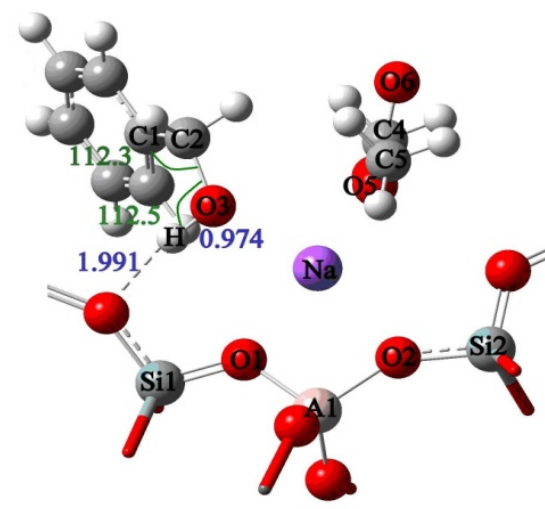

TS1

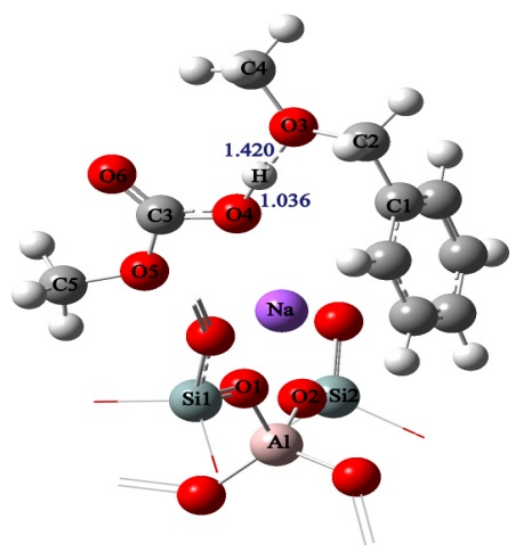

GS3

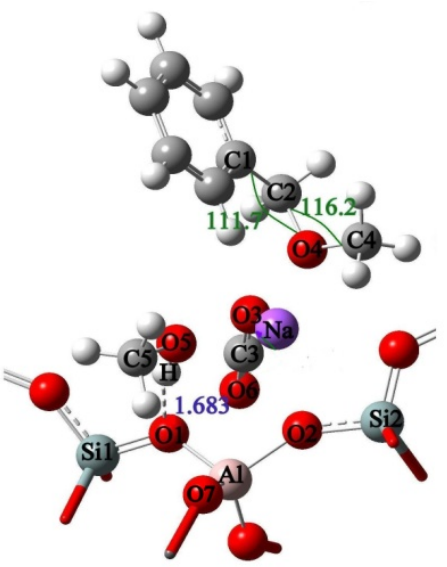

TS4

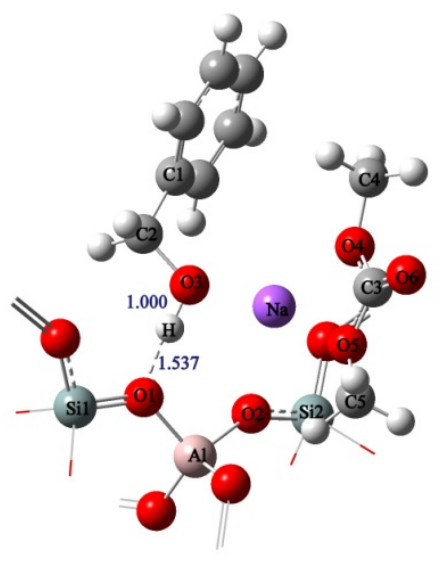

GS2

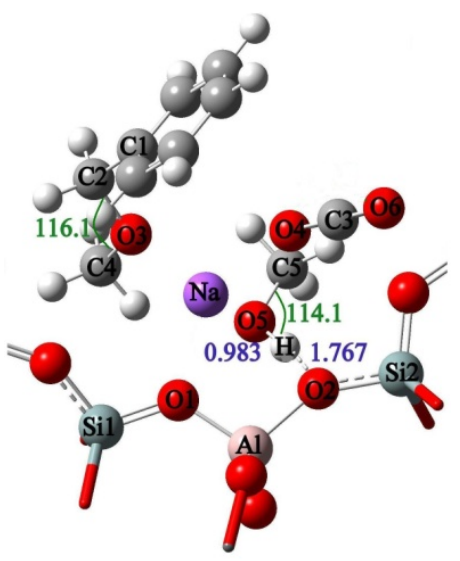

TS3

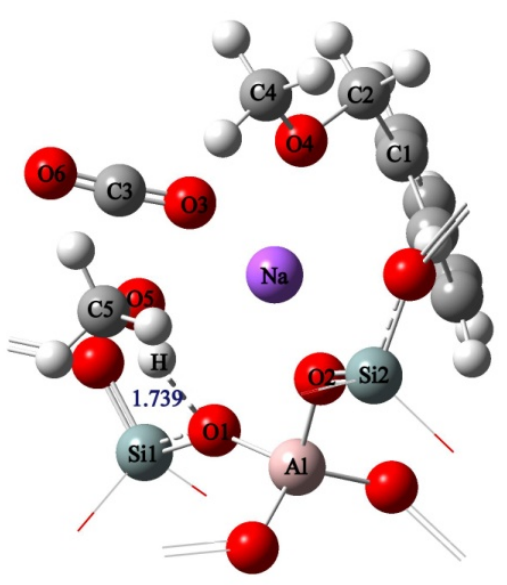

GS5 


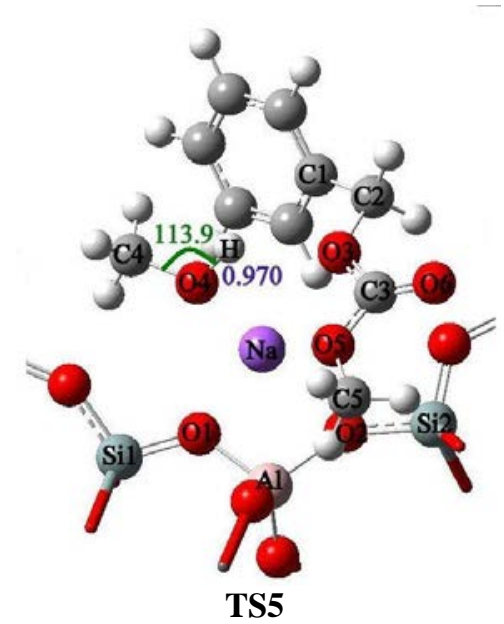

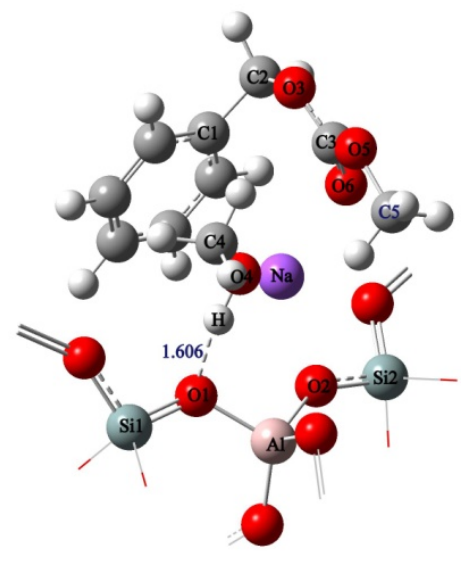

GS6

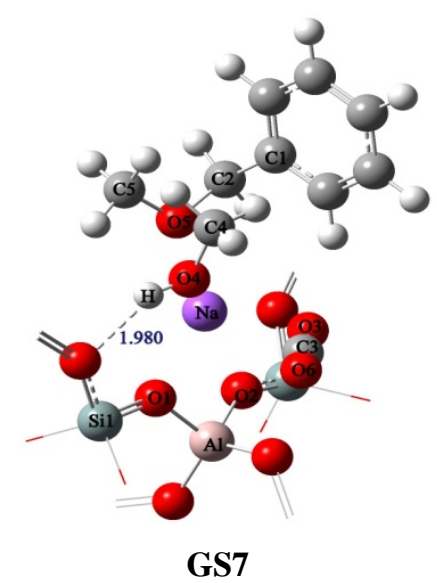

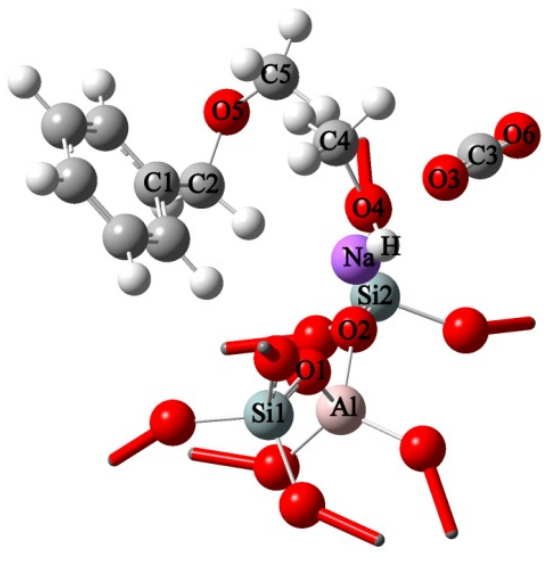

TS6

Fig. 1.1 The Optimized TSs and GSs geometries with some important bond parameters (distances are reported in $\AA$ and angles are in degrees) of the reactants over a 36T quantum cluster of zeolite

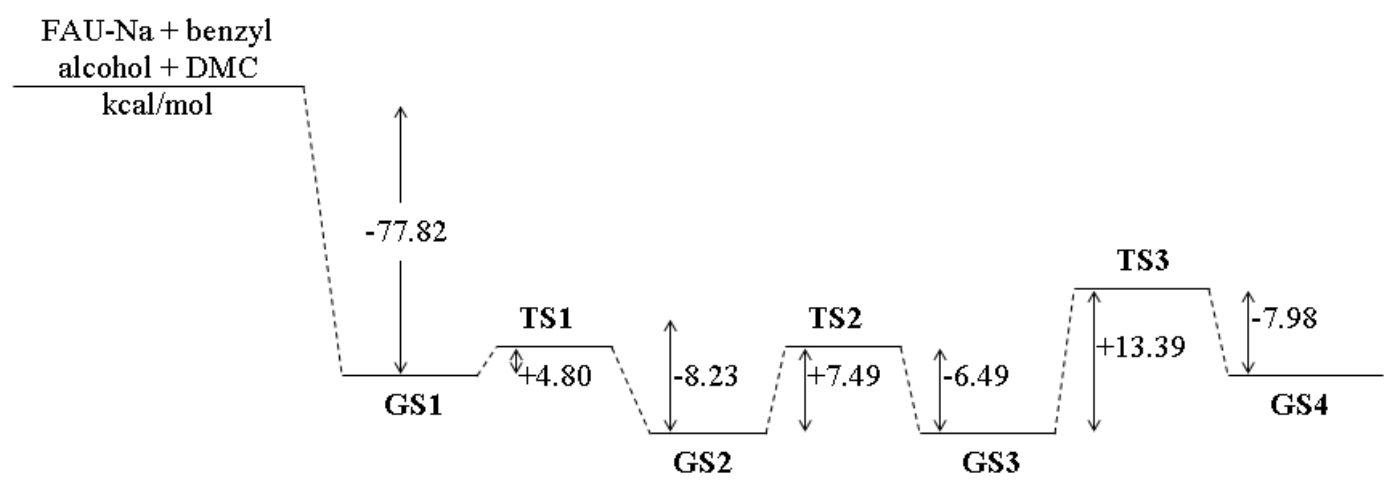

Fig. 1.2 Energy profile for the adsorption of reactants and the methylation reaction via pathway 1 , which involves two TSs (TS2 and TS3) over a 36T quantum cluster of zeolite 


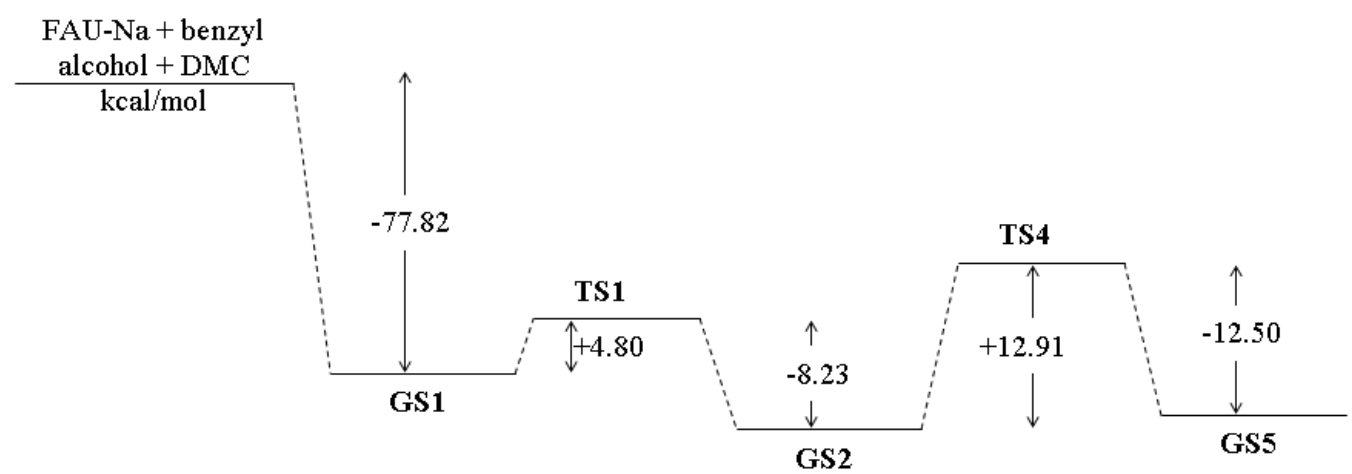

Fig. 1.3 Energy profile for the adsorption of reactants and the methylation reaction via pathway 2, which involves only a single TS (TS4) over a 36T quantum cluster of zeolite

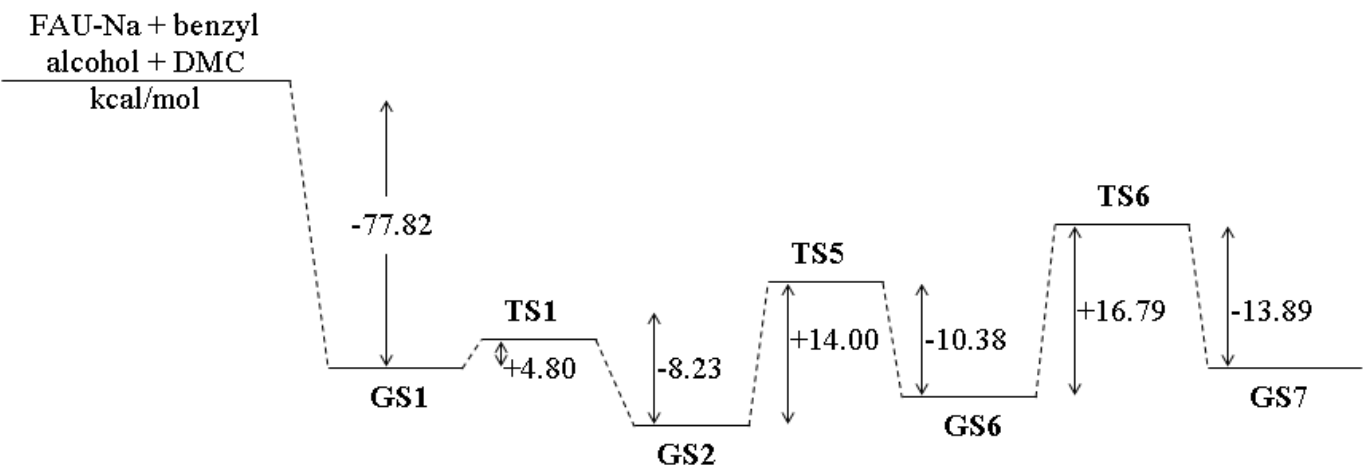

Fig. 1.4 Energy profile for the adsorption of reactants and the carboxymethylation reaction over a 36T quantum cluster of zeolite

Table 1.0 Kinetic parameters, after including Wigner's tunneling correction, for each TS

\begin{tabular}{c|c}
\hline & Rate Constant $\mathbf{~ s}^{-1}\left(10^{12}\right)$ \\
\hline Co-adsorption of reactants (TS1) & 2.409 \\
Methylation Pathway 1 (TS2) & 1.008 \\
Methylation Pathway 1 (TS3) & 2.048 \\
Methylation Pathway 2 (TS4) & 6.387 \\
Carboxymethylation (TS5) & 4.018 \\
Carboxymethylation (TS6) & 5.630 \\
\hline
\end{tabular}

\subsection{Rate Constants}

Canonical transition state theory was used to predict the rate constant, $k[22,32,33]$. The methylation and carboxymethylation reaction rate is expressed as in Eq. 10:

$k=\Gamma\left(k_{B} T / h_{p}\right) N_{A}\left(Q_{T S} / Q_{A}\right) \exp \left(-E a / k_{B} T\right)$

where $Q_{T S}$ and $Q_{A}$ are the total partition functions for the TS structure and the reactants over a 3T or a 36T cluster of zeolite at temperature $T, k_{B}$ is the Boltzmann's constant, $h_{p}$ is the Plank's constant, $N_{A}$ is Avogadro's constant, and $E_{a}$ is the activation barrier with zero point energy correction. The translational, rotational, vibrational and electronic partition functions were taken into account for the calculations [22,32]. The tunneling correction, $\Gamma$, is calculated by the following Eq. 11,

$$
\Gamma=1+1 / 24\left(h v^{\ddagger} / k_{B} T\right)^{2}
$$

where $v^{\neq}$is the imaginary frequency.

Table 1.0 shows the calculated rate constants in each TS. The rate constant for methylation reaction via reaction Pathway 2 is faster than that for Pathway 1, whilst the TS5 of the carboxymethylation reaction, which happens simultaneously with the methylation reaction at TS2. In addition, the methylation Pathway 1 (TS2) is the rate determining step. The decarboxylation reaction (TS6) was observed to be 1.40-fold faster than the carboxymethylation reaction (TS5). 


\section{CONCLUSION}

The proposed methylation and carboxymethylation reaction mechanisms of benzyl alcohol with DMC over a $36 \mathrm{~T}$ zeolite framework were investigated theoretically via ONIOM approach. The calculations shown that the methylation reactions undergo two different pathways to form BME. The methylation Pathway 1 involved two TSs to give the desired product, BME, with a carbonic acid as a side product. The unstable carbonic acid will undergo another TS (TS3) and further decompose to carbon dioxide and methanol. Pathway 2 is a one step reaction which only consist a single TS to produce BME with carbon dioxide and methanol. Calculations also have shown that the Pathway 1 is more favorable than Pathway 2, due to the lower activation energies and it is kinetically more stable. In addition, both of the methylation pathways are also kinetically more favourable than the carboxymethylation reaction and this finding agrees well with previous experimental studies which reported that the carboxymethylation reaction yielded a low percentage of products at high reaction temperature. At the end of the methylation and carboxymethylation reactions, carbon dioxide and BME were observed moving away from the zeolite surface, whilst methanol remained adsorbed onto the zeolite via a hydrogen bond. The rate constants over the $36 \mathrm{~T}$ cluster suggested that the methylation Pathway 1 (TS2) is the rate determining step.

\section{ACKNOWLEDGEMENT}

This work was supported by the School of Chemical Sciences of Universiti Sains Malaysia, Penang.

\section{REFERENCES}

[1] L.G. Wade, Jr, Organic Chemistry, sixth ed., Pearson Prentice Hall, New Jersey, 2006.

[2] F. Aguilar, H.N. Autrup, S. Barlow, L. Castle, R. Crebelli, W. Dekant, K.-H. Engel, N. Gontard, D.M. Gott, S. Grilli, R. Gürtler, J.C. Larsen, J.-C. Leblanc, C. Leclercq, F.X. Malcata, W. Mennes, M.R. Milana, I. Pratt, I.M.C.M. Rietjens, P.P. Tobback, F. Toldrá, The EFSA Journal, 833 (2008), $1-67$.

[3] H.F. Grützmacher, S. Dohmeier-Fischer, Int. J. Mass Spectrom., 179-180 (1998), 207-221.

[4] W.-C. Shieh, S. Dell, O. Repic, J. Org. Chem., 67 (7) (2002), 2188-2191.

[5] M. Selva, E. Militello, M. Fabris, Green Chem., 10 (1) (2008), 73-79.

[6] M. Selva, Pure Appl. Chem., 79 (11) (2007), 1855-1867.

[7] M. Selva, P. Tundo, A. Perosa, J. Org. Chem., 68 (19) (2003), 7374-7378

[8] P. Tundo, S. Memoli, D. Herault, K. Hillc, Green Chem., 6 (2004), 609-612.

[9] P. Tundo, M. Selva, Acc. Chem. Res., 35 (9) (2002), 706-716.

[10] P. Tundo, Pure Appl. Chem., 73 (7) (2001), 1117-1124.

[11] A.-A. G. Shaikh, S. Sivaram, Chem. Rev., 96 (1996), 951-976.

[12] D.H. Olson, Zeolites, 15 (5) (1995), 439-443.

[13] S. Kasuriya, S. Namuangruk, P. Treesukol, M. Tirtowidjojo, J. Limtrakul, J. Catal., 219 (2) (2003), $320-328$.

[14] K. Bobuatong, J. Limtrakul, Appl. Catal. A: Gen., 235 (1) (2003), 49-64.

[15] S. Namuangruk, P. Pantu, J. Limtrakul, J. Catal., 225 (2004) , 523-530.

[16] P. Wongthong, C. Soonthornpalin, P. Pantu, J. Limtrakul, Studies in Surface Science and Catalysis, Elsevier, 2004, pp. $1817-1822$.

[17] R. Rungsirisakun, B. Jansang, P. Pantu, J. Limtrakul, J. Mol. Struct., 733 (1-3) (2005), 239-246.

[18] Y.X. Sun, J. Yang, L.F. Zhao, J.X. Dai, H. Sun, J. Phys. Chem. C, 114 (13) (2010), 5975-5984.

[19] W. Panjan, J. Limtrakul, J. Mol. Struct., 654 (1-3) (2003), 35-45.

[20] S.A. Zygmunt, L. A. Curtiss, L.E. Iton, M.K. Erhardt, J. Phys. Chem., 100 (16) (1996), 6663-6671.

[21] A. Goursot, I. Papai, V. Vasilyev, F. Fajula, Studies in Surface Science and Catalysis, Elsevier, 1995, pp. 109-116.

[22] X. Zheng, P. Blowers, J. Mol. Catal. A: Chem., 246 (1-2) (2006), 1-10.

[23] M.J. Frisch, G.W. Trucks, H.B. Schlegel, G.E. Scuseria, M.A. Robb, J.R. Cheeseman, J.A. Montgomery, Jr., T. Vreven, K.N. Kudin, J.C. Burant, J.M. Millam, S.S. Iyengar, J. Tomasi, V. Barone, B. Mennucci, M. Cossi, G. Scalmani, N. Rega, G.A. Petersson, H. Nakatsuji, M. Hada, M. Ehara, K. Toyota, R. Fukuda, J. Hasegawa, M. Ishida, T. Nakajima, Y. Honda, O. Kitao, H. Nakai, M. Klene, X. Li, J.E. Knox, H.P. Hratchian, J.B. Cross, V. Bakken, C. Adamo, J. Jaramillo, R. Gomperts, R.E. Stratmann, O. Yazyev, A. J. Austin, R. Cammi, C. Pomelli, J.W. Ochterski, P.Y. Ayala, K. Morokuma, G.A. Voth, P. Salvador, J.J. Dannenberg, V.G. Zakrzewski, S. Dapprich, A.D. Daniels, M.C. Strain, O. Farkas, D.K. Malick, A.D. Rabuck, K. Raghavachari, J. B. Foresman, J.V. Ortiz, Q. Cui, A. G. Baboul, S. Clifford, J. Cioslowski, B.B. Stefanov, G. Liu, A. Liashenko, P. Piskorz, I. Komaromi, R.L. Martin, D.J. Fox, T. Keith, M. A. Al-Laham, C.Y. Peng, A. Nanayakkara, M. Challacombe, P.M.W. Gill, B. Johnson, W. Chen, M.W. Wong, C. Gonzalez, and J.A. Pople, Gaussian 03, Revision C.02, Gaussian, Inc., Wallingford CT, 2004.

[24] X. Nie, M.J. Janik, X. Guo, X., Liu, \& C. Song, C. Catalysis Today, 165 (1) (2011), 120-128.

[25] A. Zhu, X. Zhang, Q. Liu, Q. Zhang, Chinese J. Chem. Eng., 17 (2) (2009), 268-272.

[26] R.K. Khanna, J.A. Tossell, K. Fox, Icarus, 112 (2) (1994), 541-544.

[27] M.T. Nguyen, A.F. Hegarty, T.K. Ha, J. Mol. Struc.: Theochem., 150 (3-4) (1987), 319-325.

[28] M.T. Nguyen, T. K. Ha, J. Am. Chem. Soc., 106 (3) (1984), 599-602.

[29] B. Jönsson, G. Karlström, H. Wennerström, B. Roos, Chem. Phys. Lett., 41 (2) (1976), 317-320.

[30] H. Fang, A. Zheng, J. Xu, S. Li, Y. Chu, L. Chen, F. Deng, J. Phys. Chem. C, 115 (15) (2011), 7429-7439.

[31] C.A. Wight, A. I. Boldyrev, J. Phys. Chem., 99 (32) (1995), 12125-12130.

[32] F. Louis, C.A. Gonzalez, R.E. Huie, M.J. Kurylo, Phys. Chem. A, 105 (9) (2000), 1599-1604.

[33] W. Sangthong, M. Probst, J. Limtrakul, J. Mol. Struct., 748 (1-3) (2005), 119-127. 